\title{
Taxonomic notes on the rare ant genus Chrysapace with description of a new species from Brunei (Hymenoptera: Formicidae: Dorylinae)
}

\author{
Aiki YAMADA ${ }^{1, *}$, Chung-Chi LIN ${ }^{2)} \&$ Katsuyuki EGUCHI ${ }^{1)}$ \\ ${ }^{1)}$ Department of Biological Sciences, Graduate School of Science, Tokyo Metropolitan University, Tokyo, Japan \\ 2) Department of Biology, National Changhua University of Education, Changhua, Taiwan \\ *) Corresponding author; e-mail: aiki.ymd@gmail.com
}

Accepted:

$26^{\text {th }}$ August 2019

Published online: $12^{\text {th }}$ September 2019

\begin{abstract}
The genus Chrysapace Crawley, 1924 is one of the rarest and poorly known lineages in the ant subfamily Dorylinae, currently composed of only three extant valid species from the Oriental Realm. There is some taxonomic obscurity concerning the distinction between two of the three valid species, C. sauteri (Forel, 1913) and C. costatus (Bharti \& Wachkoo, 2013), resulting from previous unavailability of $C$. sauteri type material and inconsistency in descriptions provided in previous literature. In the present study, we examined the C. sauteri syntype and the C. costatus holotype as well as newly collected material and vouchers used in previous literature. Although both of the species agreed well with each other in most morphological characters of the worker, we tentatively retain the separation of these species based on differences in the head sculpture, eye and ocelli sizes. The worker, queen, and male of $C$. sauteri, and the worker of $C$. costatus are here redescribed with the first provision of COI DNA barcode data. In addition, C. merimbunensis Yamada \& Eguchi sp. nov. is described from Brunei based on workers and males from a single colony. A key to valid Chrysapace species is also provided.
\end{abstract}

Key words. Hymenoptera, Formicidae, Chrysapace costatus, Chrysapace merimbunensis, Chrysapace sauteri, male genitalia, Brunei, Oriental Realm

Zoobank: http://zoobank.org/urn:lsid:zoobank.org:pub:4CDE0401-572B-45CD-B7FE-5CC7F9C5606B

(C) 2019 The Authors. This work is licensed under the Creative Commons Attribution-NonCommercial-NoDerivs 3.0 Licence.

\section{Introduction}

The ant subfamily Dorylinae (Hymenoptera: Formicidae) is a monophyletic group of predatory ants that primarily occur in the tropics and subtropics of the world. Recently, the generic-level classification of the subfamily Dorylinae was dramatically revised by BorowIEC (2016) based on the result of molecular phylogenetic analysis and morphological reappraisal.

The genus Chrysapace Crawley, 1924 was established for the species C. jacobsoni Crawley, 1924 (type locality: Sumatra, Indonesia), and was considered a junior synonym of the genus Cerapachys F. Smith, 1857 since BRown (1975). However, it was revived as an independent genus by BOROWIEC (2016). This genus belongs to a clade together with Cerapachys and Yunodorylus $\mathrm{Xu}, 2000$ (BorowIEC 2017), and is one of the rarest and poorly known doryline lineages, currently composed of only three extant valid species (BOLTON 2019) from the Oriental Realm (sensu Holt et al. 2013). In addition, an undescribed extant species of this genus from northern Madagascar and a fossil species from Baltic amber are known (unpublished data referred to in BOROwIEC 2016).

There is some taxonomic obscurity concerning the distinction between two of the three valid species, $C$. sauteri (Forel, 1913) and C. costatus (Bharti \& Wachkoo, 2013), which are morphologically very similar to each other. The former species was originally described from Taiwan based on the worker caste. TERAYAMA et al. (1998) redescribed this species with description of the male and queen based on newly collected materials from Taiwan. The latter species was recently described based on a single worker (holotype) from Uttarakhand in northern 
India, and then was recorded from Guangxi in China by Chen et al. (2016). However, the type specimen of $C$. sauteri has never been re-examined since its original description, and the morphological distinctions between these two species reported by BHARTI \& WACHKOо (2013) appear inconsistent with the redescription of $C$. sauteri in Terayama et al. (1998).

In the present study, we examined the $C$. costatus holotype as well as newly collected material and vouchers used in CHEN et al. (2016) and TERAYAma et al. (1998), by referring to the images of the $C$. sauteri syntype (available in AntWeb, https://www.antweb.org/). Although both $C$. sauteri and $C$. costatus agreed well with each other in most morphological characters of the worker, we tentatively retain the separation of these species based on differences in the head sculpture, eye and ocelli sizes. Both species are here redescribed, with the first provision of COI DNA barcode data. In addition, C. merimbunensis sp. nov. is described from Brunei based on workers and males from a single colony. A key to valid Chrysapace species is also provided.

\section{Material and methods}

Specimen depositories. Abbreviations for specimen depositories are as follows:

\begin{tabular}{|c|c|}
\hline $\mathrm{AKYC}$ & Ant Collection of A. Yamada; \\
\hline ACEG & Ant Collection of K. Eguchi; \\
\hline DEIC & $\begin{array}{l}\text { Senckenberg Deutsches Entomologisches Institut, Münche- } \\
\text { berg, Germany; }\end{array}$ \\
\hline GNU & $\begin{array}{l}\text { Key Laboratory of Ecology of Rare and Endangered Species } \\
\text { and Environmental Protection, Guangxi Normal University } \\
\text { Guilin, China; }\end{array}$ \\
\hline MBD & Museum Brunei, Bandar Seri Begawan, Brunei; \\
\hline MHNG & Muséum d'Histoire Naturelle, Geneva, Switzerland; \\
\hline MTC & Ant Collection of Mamoru Terayama; \\
\hline PUPAC & Punjabi University Patiala Ant Collection, Patiala, India; \\
\hline TARI & Taiwan Agricultural Research Institute, Taichung, Taiwan. \\
\hline
\end{tabular}

Morphological examination and imaging. Male genitalia were cleaned using the Chelex-TE protocol (for details see SATRIA et al. 2015), and then dehydrated in $99 \%$ ethanol, dissected into several main components in a small amount of Euparal on a slide glass, and covered with a cover slip.

Source images for focus stacking were taken using a Canon EOS Kiss X9 digital camera attached to a Nikon AZ100 stereomicroscope (for the body excluding male genitalia) and Nikon Eclipse E600 microscope (for male genitalia). Focus stacked images were produced by Helicon Focus Pro 7.0.2, and then improved using the retouching function of Helicon Focus. Finally, the color balance, contrast, and sharpness were adjusted using Adobe Lightroom Classic CC 8.1 and GIMP 2.10 (The GIMP Development Team, available at http://www.gimp.org/).

The morphological terminology follows BOROwIEC (2016) for body and Boudinot (2013) for male genitalia. Photographs for measurements were taken using a Canon Eos Kiss X9 digital camera attached to a Nikon AZ100 microscope, or Keyence VHX-6000 digital microscope under suitable magnifications (except for a C. sauteri syntype, which was examined based on images in AntWeb, https://www.antweb.org/), and the following parts of bodies were measured using ImageJ $1.52 \mathrm{a}$ (National Institute of Mental Health, USA, available at http://imagej.nih. gov/ij/) and then indices calculated. The measurements partly follow Hita Garcia et al. (2017) and BOLTON \& FISHER (2012) with minor modifications, or are used here for the first time:

HL Head Length: maximum length of cranium in full-face view, measured from transverse line spanning posteromost points of cranium to that spanning the anteromost points of clypeus (or to tangent line of the anteromost point of clypeus in $C$. merimbunensis where median portion of anterior clypeal margin protrudes beyond anterior margin of lateral portion of clypeus);

HW Head Width: maximum width of cranium in full-face view (excluding eyes);

EL Eye Length: maximum length of major axis of eye in lateral view;

EW Eye Width: maximum length of minor axis of eye that is perpendicular to EL in lateral view;

ES Eye Size: $(E L+E W) / 2$;

PEHL Post-Eye Head Length: length between transverse line spanning the anteromost points of eyes and that of posteromost points of cranium in full-face view;

OL Ocellus Length: maximum length of major axis of median ocellus;

SL Scape Length: maximum length of antennal scape excluding basal condylar bulb;

WL Weber's Length of mesosoma: maximum diagonal distance of mesosoma in lateral view, measured from the angle at which the pronotum meets the cervix to posteroventral angle of metapleuron;

DML Dorsal Mesosomal Length: length of mesosomal dorsum from midpoint of anterodorsal margin of pronotum to midpoint of dorsal margin of propodeal declivity in dorsal view;

MW Mesosomal Width: maximum width of mesosoma in dorsal view;

PH Pronotal Height: maximum height of the pronotum in lateral view (for worker only);

MSL Mesoscutum Length: maximal length of mesoscutum in dorsal view (for queen and male only);

MSW Mesoscutum Width: maximal width of mesoscutum in dorsal view (for queen and male only);

MFL Metafemoral Length: the maximum length of the metafemur, measured in dorsal view;

PTL Petiolar Length: maximum length of petiole in dorsal view (excluding helcium);

PTW Petiolar Width: maximum width of petiole in dorsal view;

A3L Abdominal Segment III Length: maximum length of abdominal segment III in dorsal view;

A3W Abdominal Segment III Width: maximum width of abdominal segment III in dorsal view;

CI Cephalic Index: HW / HL $\times 100$;

EI Eye Index: ES $/ \mathrm{HW} \times 100$;

EPI Eye Position Index: PEHL $/ \mathrm{HL} \times 100$;

OI Ocellus Index: OL $/ \mathrm{HW} \times 100$;

SI Scape Index: SL / HW $\times 100$;

DMI Dorsal Mesosoma Index: MW / DML × 100;

DMI2 Dorsal Mesosoma Index 2: DML / WL $\times 100$;

LMI Lateral Mesosoma Index: PH / DML $\times 100$ (for worker only);

MFI Metafemur Index: MFL $/ \mathrm{HW} \times 100$;

PTI Petiolar Index: PTW / PTL $\times 100$;

A3I Abdominal Segment III Index: A3W / A3L × 100;

MSI Mesocutum Index: MSW/MSL $\times 100$ (for queen and male only).

DNA barcoding. Two nontype workers of $C$. sauteri and a nontype worker of $C$. costatus were used for DNA barcoding (see under "Material used for DNA barcoding"). DNA extraction was conducted using the Chelex-TE protocol (for details see SATRIA et al. 2015). A 658 bp region (Folmer region) of the mitochondrial cytochrome 
c oxidase subunit I (COI) gene was amplified using the primers LCO-EG and HCO-EG (modified from FOLMER et al. 1994: 5'-TTTCAACAAATCACAAAGAYATYGG-3' and 5'-TAAACTTCAGGRTGACCRAAAAATCA-3'). PCR amplifications, cycle sequencing reactions, sequencing using ABI PRISM 3130xl (Applied Biosystems), and sequence assembly using ChromasPro 1.7.6 (Technelysium Pty Ltd., Australia) were conducted by following the protocols presented in SATRIA et al. (2015). The PCR thermal regime consisted of one cycle of 2 min at $94{ }^{\circ} \mathrm{C}$; five cycles of $10 \mathrm{sec}$ at $98{ }^{\circ} \mathrm{C}, 30 \mathrm{sec}$ at $45^{\circ} \mathrm{C}$ and $45 \mathrm{sec}$ at $68{ }^{\circ} \mathrm{C}$; 40 cycles of $10 \mathrm{sec}$ at $98{ }^{\circ} \mathrm{C}, 30 \mathrm{sec}$ at $48.5^{\circ} \mathrm{C}$ and $45 \mathrm{sec}$ at $68^{\circ} \mathrm{C}$; and a final cycle of $7 \mathrm{~min}$ at $68^{\circ} \mathrm{C}$. Successful assembly of each sequence was confirmed by translating it to the amino acid sequence and checking the absence of frame shifts caused by erroneous indels. The final sequences were submitted to International Nucleotide Sequence Database (INSD: http://www.insdc.org) via the DNA Data Bank of Japan (DDBJ) and are available under GenBank accession numbers LC457501-LC457503.

\section{Taxonomy}

\section{Genus Chrysapace Crawley, 1924}

Chrysapace Crawley, 1924: 380. Type species: Chrysapace jacobsoni Crawley, 1924 (junior secondary homonym in Cerapachys, replaced by Cerapachys crawleyi W. M. Wheeler, 1924), by monotypy.

Diagnosis. This genus can be recognized by a combination of the following characteristics of the worker caste: i) prominent costate sculpture on most of body surface, ii) large eyes, iii) exposed antennal sockets, iv) two spurs on mid and hind tibiae, and v) pretarsal claws with a tooth (Borowiec 2016).

Key to Chrysapace species based on the worker caste. The key to valid species is provided below. Known distribution is shown in the parentheses after species name. Our knowledge on C. jacobsoni is based on its original description (Crawley 1924), Wheeler (1924), and Brown (1975).

1 Abdominal tergite IV-VI longitudinally costate (except for anterior marginal areas); dorsum of mesosoma transversely arched in most areas.

C. jacobsoni Crawley, 1924

(Sumatra, Borneo, Philippines)

- Abdominal tergite IV-VI lacks any costation; dorsum of mesosoma longitudinally costate.

2 Abdominal tergite III with costae which are transversely arched around center of posterior margin in dorsal view (Fig. 5).

C. merimbunensis sp. nov.

(Brunei)

- Abdominal tergite III longitudinally costate. ............. 3

3 Costae on vertex at most weakly distorted (Fig. 41); eye and ocelli relatively small $(\mathrm{EI}+\mathrm{OI} \leqq 25)$.

C. sauteri (Forel, 1913)

(Taiwan)

- Costae on vertex strongly and coarsely distorted (Figs $42-43)$; eye and ocelli relatively large (EI + OI $\geqq 29)$.

C. costatus (Bharti \& Wachkoo, 2013)

(northern India, Yunnan, Guangxi)

\section{Chrysapace merimbunensis Yamada \& Eguchi sp. nov. (Figs 1-19)}

Type material examined. HоLотуре: $\not$, Tasek Merimbun, Tutong, Brunei, K. Eguchi leg., 17.viii.1999, colony: Eg99-BOR-590 (MBD). PARATYPES: $1 \Varangle, 3 \precsim$ from the same colony as the holotype (MBD; MHNG).

Diagnosis. In the worker, cranium subtrapezoidal in fullface view; dorsum of mesosoma longitudinally costate; abdominal tergite III with costae which are transversely arched around center of posterior margin in dorsal view (Fig. 5); abdominal sternite III longitudinally costate; cinctus of abdominal segment IV smooth without any costae; abdominal tergite and sternites IV smooth with sparse hair-bearing foveae.

Description. Worker (Figs 1-8). Body black; antennae, anterior part of cranium, mandibles, and legs reddish brown. Body pilosity relatively sparse.

Cranium in full-face view subtrapezoidal, wider posteriorly than anteriorly, faintly longer than wide (CI, 95-96); posterior part of cranium above eyes relatively short (EPI, 16-17), with PEHL much shorter than EL. Median ocellus located close to level of posteromost points of eyes in fullface view. Torulo-posttorular complex in full-face view relatively broad and partially concealing antennal socket; width, when measured at level of antennal socket, distinctly greater than length of major axis of antennal socket; lateral margin almost straight but slightly undulate, slightly converging posteriad; anterior protrusion of anterolateral lobe encircling antennal socket weak, not distinctly protruding beyond anterior margin of lateral portion of clypeus in full-face view. Median portion of anterior clypeal margin weakly convex in full-face view, protruding beyond anterior margin of lateral portion of clypeus. Antenna 12-segmented. Maxillary palp 5-segmented. Labial palp 3 -segmented. Mandible elongate, with relatively acute apex; masticatory margin feebly dentate, in dorsal view longer than twice as long as basal margin; ventral face of mandible with a series of modified setae along masticatory margin. Mesosoma in dorsal view relatively stout (DMI, 73), with evenly rounded lateral margins. Dorsal margin of propodeal declivity in dorsal view strongly arched anteriad and margined by strong edge. Petiole in dorsal view subtrapezoidal, wider posteriorly than anteriorly, with strongly convex lateral margin. Anterodorsal corner of abdominal tergite III forming sharp edge (arrow in Fig. 2). Anteroventral corner of abdominal sternite III (prora) in lateral view strongly angulate with acute apex directed ventrad. Posterior margin of pygidium in dorsal view weakly concave medially.

Costae on body smoothly running, without overlaying microsculpture. Frons and vertex transversely costate (Fig. 1). Posterolateral face of cranium and posterior face above preoccipital carina longitudinally costate (Figs 2-3). Torulo-posttorular complex and clypeus largely smooth. Gena largely smooth on face inside parafrontal ridge, whereas weakly coarsely rugose on face outside the ridge. Outer face of antennal scape longitudinally rugulate-striate on about basiposterior diagonal half, whereas smooth on remaining face. Outer face of mandible smooth (Fig. 4). 


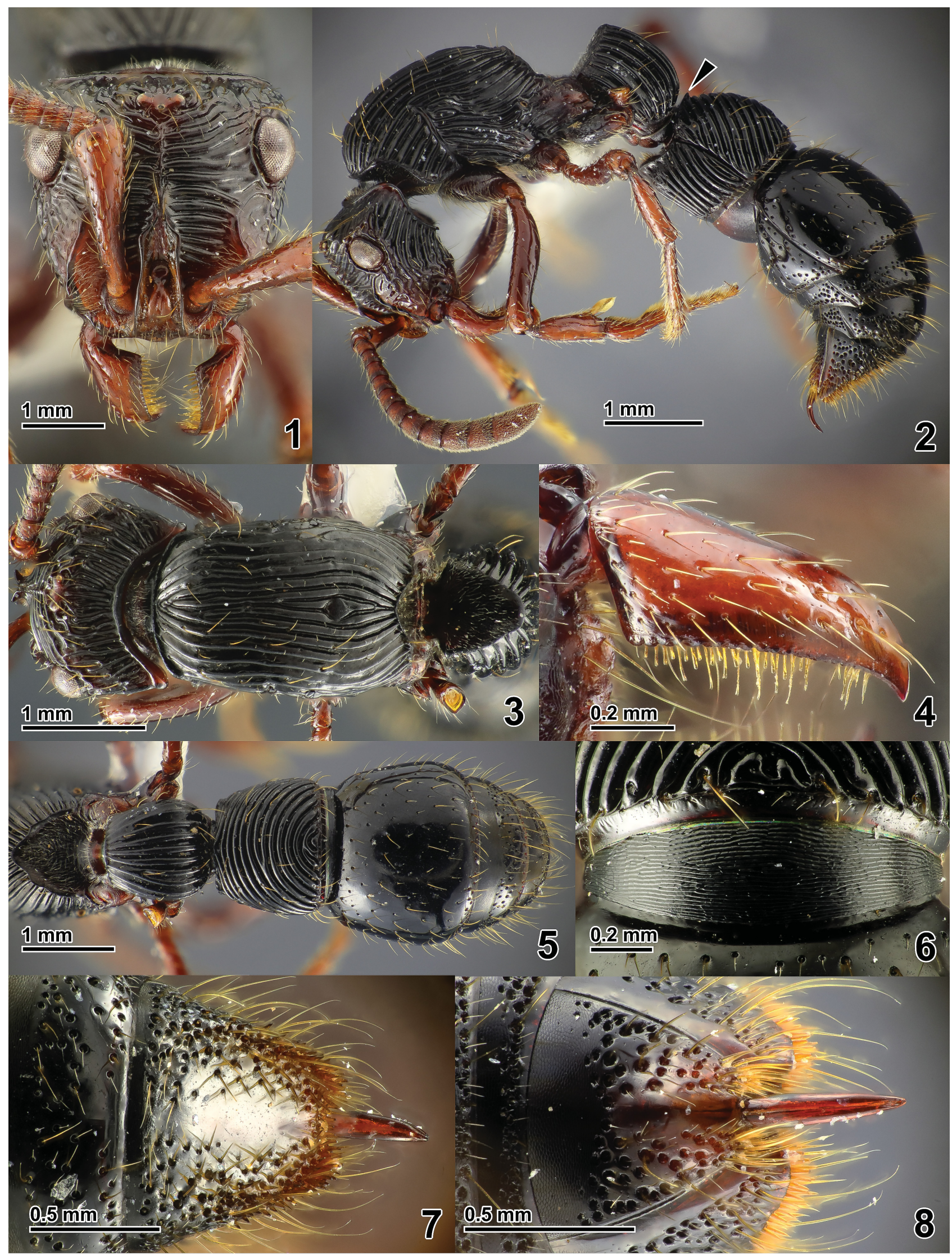

Figs 1-8. Chrysapace merimbunensis Yamada \& Eguchi sp. nov., worker, holotype (except for Fig. 6 which is based on a paratype). 1 - head in full-face view; 2 - body in lateral view; 3 - head and mesosoma in dorsal view; 4 - left mandible in dorsal view; 5 - metasoma in dorsal view; 6 - pretergite and cinctus of abdominal segment IV in dorsal view; 7 - pygidium in dorsal view; 8 - hypopygium in ventral view. 


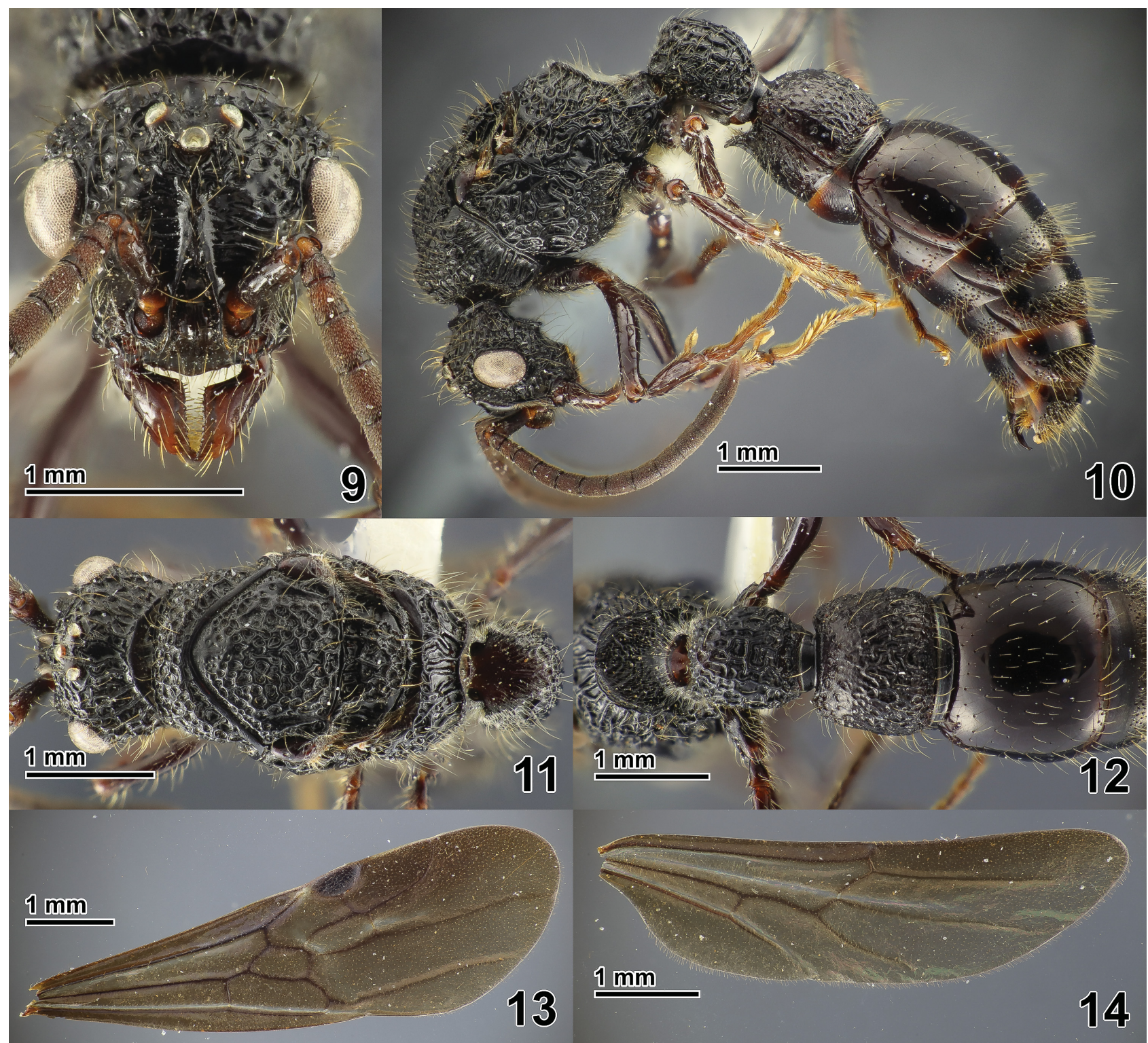

Figs 9-14. Chrysapace merimbunensis Yamada \& Eguchi sp. nov., male, paratype. 9 - head in full-face view; 10 - body in lateral view; 11 - head and mesosoma in dorsal view; 12 - metasoma in dorsal view; 13 - right forewing in dorsal view; 14 - right hindwing in dorsal view.

Promesonotum, dorsal and lateral face of propodeum longitudinally costate. Mesopleuron with oblique-longitudinal costae which run parallelly with anteroventral margin of mesopleuron. Metapleuron partly costate weakly and longitudinally. Posterior declivity of propodeum smooth. Legs largely smooth, with each coxa partly shagreened. Anterior face of petiole smooth; dorsal and lateral faces of petiolar tergite longitudinally costate. Posterodorsal face of helcium imbricate, without any costae. Costae on abdominal tergite III with costae which are transversely arched around center of posterior margin in dorsal view (see Figs 2, 5). Abdominal sternite III longitudinally costate. Pretergite and presternite of abdominal segment IV transversely striate (but partly imbricate, Fig. 6). Cinctus of abdominal segment IV (boundary between pre- and postsclerites) smooth without any costae. Abdominal posttergite and poststernite IV smooth, with sparse hair-bearing foveae. Abdominal tergites and sternites V-VI imbricate on anterior marginal areas, whereas smooth, with relatively dense hair-bearing foveae on remaining face. Pygidium and hypopygium imbricate on anterior marginal area, whereas smooth submedially with dense hair-bearing foveae on remaining face (Figs 7-8).

Holotype worker (paratype worker in the parentheses). HL 1.63 (1.57) mm; HW 1.56 (1.50) mm; EL 0.39 (0.38) mm; EW 0.27 (0.27) mm; ES 0.33 (0.32) mm; PEHL 0.28 (0.24) mm; OL 0.05 (0.04) mm; SL 1.12 (1.05) mm; WL 2.63 (2.51) mm; DML 1.96 (1.85) mm; MW 1.43 (1.35) mm; MFL 1.70 (1.63) mm; PH 1.15 (1.12) mm; PTL 1.13 (1.11) mm; PTW 1.06 (0.97) mm; A3L 1.21 (1.27) mm; A3W 1.43 (1.37) mm; CI 96 (95); SI 72 (70); EI 21 (22); EPI 17 (16); OI 3 (3); DMI 73 (73); DMI2 74 (74); LMI 59 (60); MFI 109 (109); PTI 94 (87); A3I 119 (107).

Male (Figs 9-19). Body black; antennae, mandibles, and legs dark reddish brown. Body pilosity relatively dense.

Cranium in full-face view bulb-shaped, just faintly longer than wide (CI, 98-99); posterolateral corner somewhat angulate; vertex not strongly raised, without concealing 


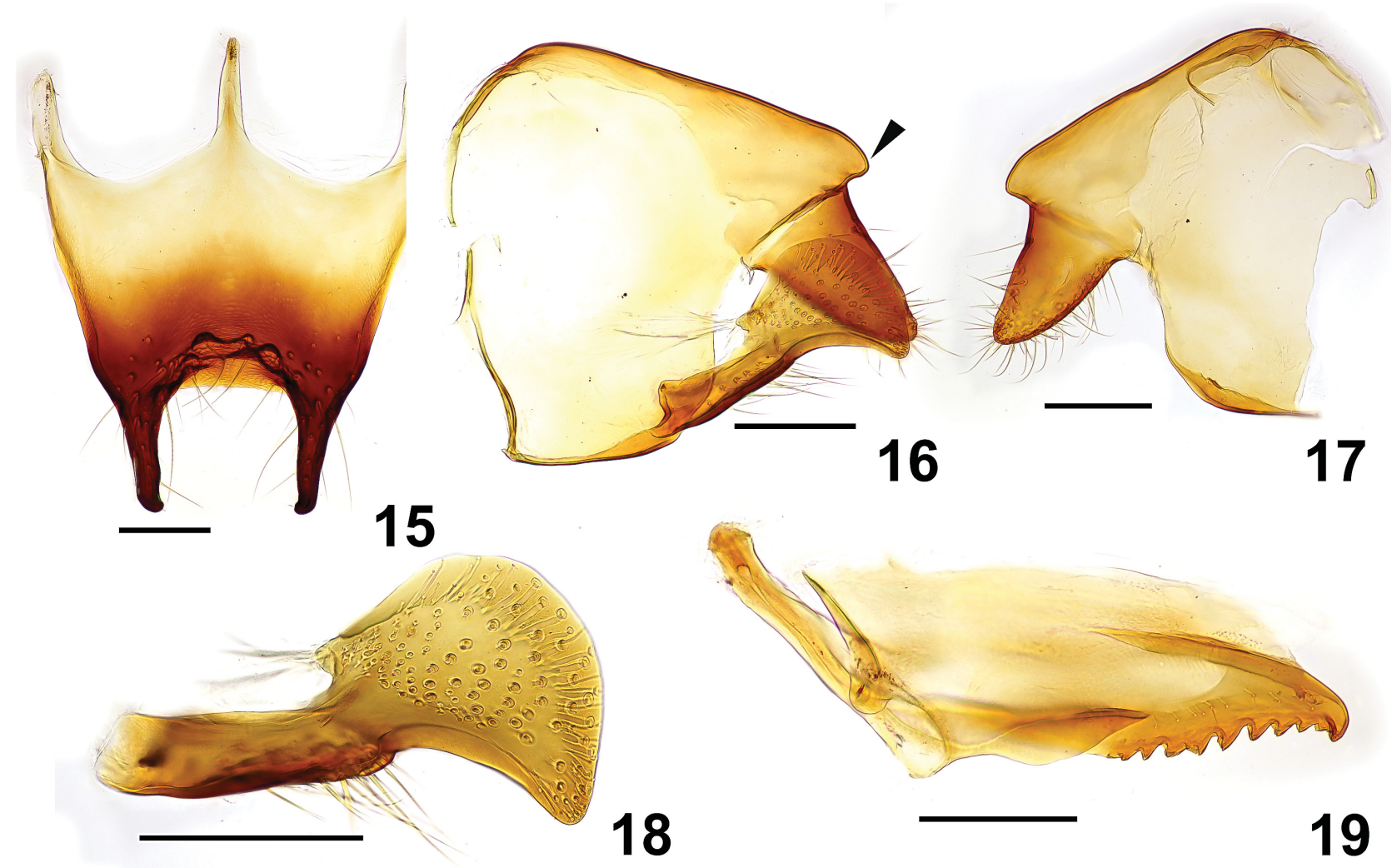

Figs 15-19. Male genitalia of Chrysapace merimbunensis Yamada \& Eguchi sp. nov., paratypes. 15 - abdominal sternite IX in ventral view; 16 - right paramere and volsella in mesal view; 17 - left paramere in mesal view, volsella removed; 18 - right volsella in mesal view; 19 - left penisvalva in lateral view. Scale bars $=0.2 \mathrm{~mm}$.

dorsal edge of preoccipital collar in full-face view. Eye and ocelli relatively small (EI, 32-33; OI, 10); median ocellus located close to level of posteromost points of eyes in full-face view. Torulo-posttorular complex in full-face view relatively broad, partially concealing antennal socket; width, when measured at level of antennal socket, distinctly greater than length of major axis of antennal socket; lateral margin parallel in short anterior part, but linearly converging posteriorly; anterior protrusion of anterolateral lobe encircling antennal socket weak. Anterior clypeal margin in full-face view strongly convex. Antenna 13-segmented. Maxillary palp 5-segmented. Labial palp 3-segmented. Mandible elongate, with relatively acute apex; masticatory margin feebly dentate, in dorsal view about twice as long as basal margin; ventral face of mandible with a series of modified setae along masticatory margin. Mesoscutum subpentagonal, a little wider than long (MSI, 118-119), with faintly convex anterolateral margin; notaulus completely absent; parapsidal line present as very weak and thin furrow. Scuto-scutellar suture fairly deep and broad, strongly scrobiculate. Posterior margin of mesoscutellum in dorsal view strongly convex. Dorsal margin of propodeal declivity in dorsal view broadly and shallowly arched anteriad, and forming strong edge. Wing venation as generic redescription in Borowiec (2016) (Figs 13-14). Petiole in dorsal view subtrapezoidal, wider posteriorly than anteriorly, with weakly convex lateral margin. Dorsal outline of abdominal tergite III in lateral view strongly rounded convex, without anterodorsal angle. Anteroventral corner of abdominal sternite III (prora) in lateral view strongly produced, with acute apex directed ventrad.

Frons weakly transversely costate. Vertex, lateral and posterior face of cranium coarsely reticulate. Torulo-posttorular complex and clypeus largely smooth. Outer face of antennal scape largely longitudinally rugulate-striate, with smooth apical face. Outer face of mandible smooth. Pronotum coarsely reticulate on dorsal face, whereas weakly and coarsely longitudinally rugose on lateral face. Mesopleuron, metapleuron, and lateral face of propodeum coarsely and irregularly rugoso-reticulate. Mesoscutum coarsely foveolate-reticulate. Mesoscutellum coarsely reticulate. Dorsum of propodeum longitudinally costate. Posterior declivity of propodeum smooth. Legs largely smooth, with meso- and metacoxae partly coarsely shagreened. Anterior face of petiole smooth; dorsal and lateral faces of petiolar tergite coarsely rugoso-reticulate. Posterodorsal face of helcium imbricate, without any costae. Abdominal tergite and sternites III largely weakly coarsely rugoso-reticulate. Pretergite and presternite of abdominal segment IV transversely striate (but partly imbricate). Cinctus of abdominal segment IV (the boundary between pre- and postsclerites) smooth, without any costae. Abdominal posttergite and poststernite IV smooth, with sparse hair-bearing foveae. Abdominal tergites and sternites V-VII imbricate on anterior marginal areas, whereas smooth with dense hair-bearing foveae on remaining face. Pygidium 
with dense hair-bearing foveae.

Spiculum (anterior apophysis) of abdominal sternite IX (Fig. 15) 0.30-0.31 times as long as entire length of sternite IX when spiculum length measured from transverse line spanning posteromost points of each anterolateral margin; outer margin of posterior spine of sternite IX in ventral view weakly concave; posteromedian flange between bases of posterior spines narrow, with some large irregular foveae along anteroventral margin of flange. Posterodorsal part of basimere in lateral view weakly broadly produced (arrow in Fig. 16); articulation of basimere to teromere have thickened margin followed by membranous articulation (Figs 16-17). Telomere in lateral view subtriangular, 1.1-1.3 times as long as wide. Cuspis absent. Digitus in lateral view claw-shaped, entirely hooked ventrad with relatively acute apex (Fig. 18). Posterior apex of valviceps in lateral view strongly hooked ventrad, with large acute apical denticle; posterior half of ventral margin having 10-12 broad denticles (including apical denticle, Fig. 19); anteroventral part of valviceps reduced, in lateral view concealed by lateral apodeme.

Paratype males $(\mathrm{n}=3)$. HL 1.31-1.33 mm; HW 1.29-1.32 mm; EL 0.47-0.50 mm; EW 0.34-0.38 mm; ES 0.41-0.44 mm; PEHL 0.36-0.37 mm; OL 0.12-0.13 mm; SL 0.54-0.57 mm; WL 2.67-2.80 mm; DML 2.32-2.38 mm; MW 1.70-1.76 mm; MSL 1.09-1.14 mm; MSW 1.30-1.35 mm; MFL 1.50-1.55 mm; PTL 0.91-0.96 mm; PTW 0.82-0.87 mm; A3L 1.06-1.12 mm; A3W 1.20-1.26 mm; CI 98-99; SI 42-44; EI 32-33; EPI 27-28; OI 10; DMI 73-74; DMI2 85-87; MSI 118-119; MFI 117-119; PTI 88-90; A3I 113-114.

Remarks. Chrysapace merimbunensis sp. nov. is relatively similar to $C$. sauteri and its sibling species $C$. costatus by sharing the following characteristics of the worker: i) dorsum of mesosoma, petiolar tergite, and abdominal sternite III longitudinally costate; ii) abdominal tergite IV-VI lacks any costation. However, the worker of the former is easily distinguished from those of the latter two species by subtrapezoidal shape of cranium in full-face view, non-costate posterodorsal face of helcium, abdominal tergite III with costae which are transversely arched around center of posterior margin in dorsal view, and non-costate cinctus of abdominal segment IV. A worker and a male of C. merimbunensis from the same colony as the type series, whose images are provided in Antweb, were once misidentified as C. sauteri (https://www.antweb.org/specimen/ CASENT0179562; CASENT0179567 [Date accessed: 30 January 2019]). The queen of C. merimbunensis is currently unknown.

In this genus the male was previously described only for C. sauteri by TERAYAma et al. (1998). Our comparison of the male morphology of $C$. merimbunensis and $C$. sauteri highlights that the male genitalia are highly differentiated between these species, especially in the shape of posterior spines and posteromedian flange of abdominal sternite IX, shape of posterodorsal projection of basimere, thickness of articulation of basimere and telomere, shape of telomere, shape of digitus, and shape of valviceps. These characters are likely to be useful for taxonomy at the species level.
Etymology. This species is named after the type locality, Tasek Merimbun (Brunei, Tutong), adjective.

Distribution. Only known from the type locality, Tasek Merimbun (Brunei, Tutong).

\section{Chrysapace sauteri (Forel, 1913) (Figs 20-41)}

Cerapachys sauteri Forel, 1913: 187, $\not$. Type locality: "Taihorin [= Dalin]" (Chiayi, Taiwan); Terayama et al. (1998: 35,,,+ , $\left.{ }^{\prime}\right)$. Chrysapace sauteri: BOROWIEC (2016): 106 (new combination).

Type material examined. SYNTYPE: $\stackrel{\square}{,}$, Dalin, Chiayi, Taiwan, H. Sauter leg. [not shown in label, implied in Forel (1913)], 1.vii.1911 (DEIC) [images in AntWeb were examined (https://www.antweb.org/specimen/ FOCOL0376)].

Other material examined. TAIWAN: 1 , Nanfen Cun, Nantou, M Terayama leg., 14.viii.1985 (MTC); 2 후, 3 ㅅํ, Wushe, Nantou, M. Terayama leg., 22.viii.1987 (MTC); 2 우, 1 ㅇ (dealate), 24.08982 N, $121.03208^{\circ}$ E, $694 \mathrm{~m}$ alt., Huisun Forest, Nantou, K. Eguchi leg., 12.v.2017, colony: Eg12v17-1214 (TARI, ACEG); 3 \% 1 (dealate), $21.97^{\circ} \mathrm{N}, 120.80^{\circ} \mathrm{E}, 250-300 \mathrm{~m}$ alt., Kenting Forest recreation area, Kenting National Park, Pingtung, 26.vii.2016, A. Yamada leg., colony: AKY26vii16-17 (TARI, AKYC)

Material used for DNA barcoding. Colony AKY26vii1 6-17 (individual no. AKY20170502-21, accession no. LC457502); colony Eg12v17-1214 (AIK20170806-1, LC457501). Pairwise distance (proportion of different sites) between the two COI sequences is 0.012 (based on $658 \mathrm{bp}$ ).

Diagnosis. In the worker, cranium subrectangular in fullface view, with costae on vertex just weakly distorted; eye and ocelli relatively small (EI + OI, 23-25); dorsum of mesosoma longitudinally costate; abdominal tergite and sternite III longitudinally costate; abdominal tergite and sternites IV smooth with relatively dense hair-bearing foveae.

Redescription. Worker (Figs 20-27, 41). Body black; antennae, anterior part of cranium, mandibles, and legs dark reddish brown. Body pilosity relatively dense.

Cranium in full-face view subrectangular with subparallel lateral margins, longer than wide (CI, 83-88); posterior part of cranium above eyes relatively long (EPI, 21-25), with PEHL distinctly longer than EL. Eye and ocelli relatively small (EI, 18-20; OI, 4-6; EI + OI, 23-25). Median ocellus located a little posteriorly to midlength of posterior part of cranium above eyes in full-face view. Torulo-posttorular complex in full-face view relatively narrow and never concealing antennal socket; width, when measured at level of antennal socket, about as long as length of major axis of antennal socket; lateral margin subparallel and weakly broadly concave; anterior protrusion of anterolateral lobe encircling antennal socket strong, exceeding anterior margin of lateral portion of clypeus in full-face view. Median portion of anterior clypeal margin weakly convex in full-face view, not protruding beyond anterior margin of lateral portion of clypeus. Antenna 12-segmented. Maxillary palp 5-segmented. Labial palp 3 -segmented. Mandible relatively short with blunt apex; masticatory margin feebly dentate, in dorsal view distinctly shorter than twice as long as basal margin; ventral face of mandible with a series of modified setae along masticatory margin. Mesosoma in dorsal view relatively slender (DMI, 64-69), with rough lateral margins. Posterodorsal margin of propodeum in dorsal view weakly arched anteriad and 


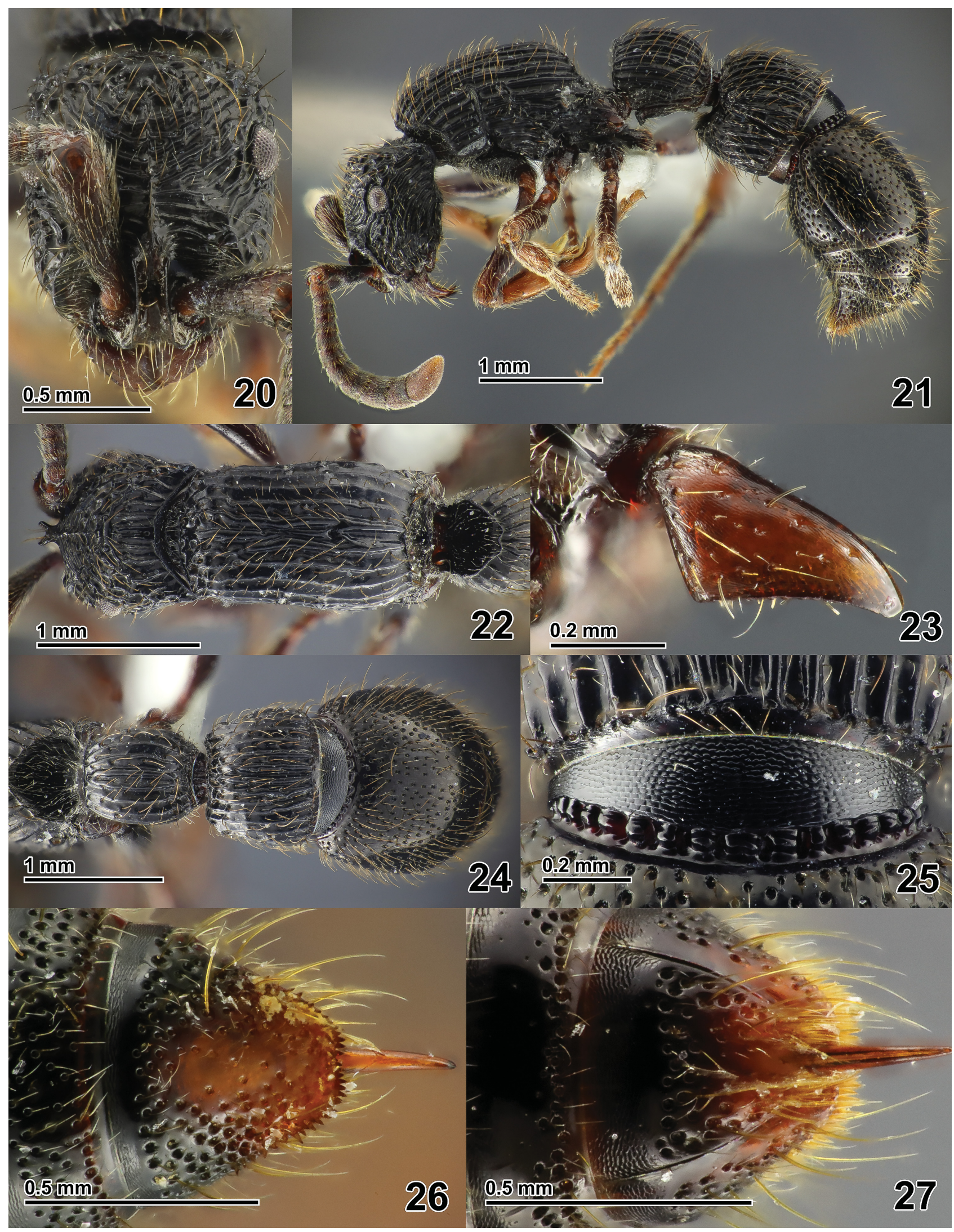

Figs 20-27. Chrysapace sauteri (Forel, 1913), nontype worker from Taiwan, colony: Eg12v17-1214. 20 - head in full-face view; 21 - body in lateral view; 22 - head and mesosoma in dorsal view; 23 - left mandible in dorsal view; 24 - metasoma in dorsal view; 25 - pretergite and cinctus of abdominal segment IV in dorsal view; 26 - pygidium in dorsal view; 27 - hypopygium in ventral view. 


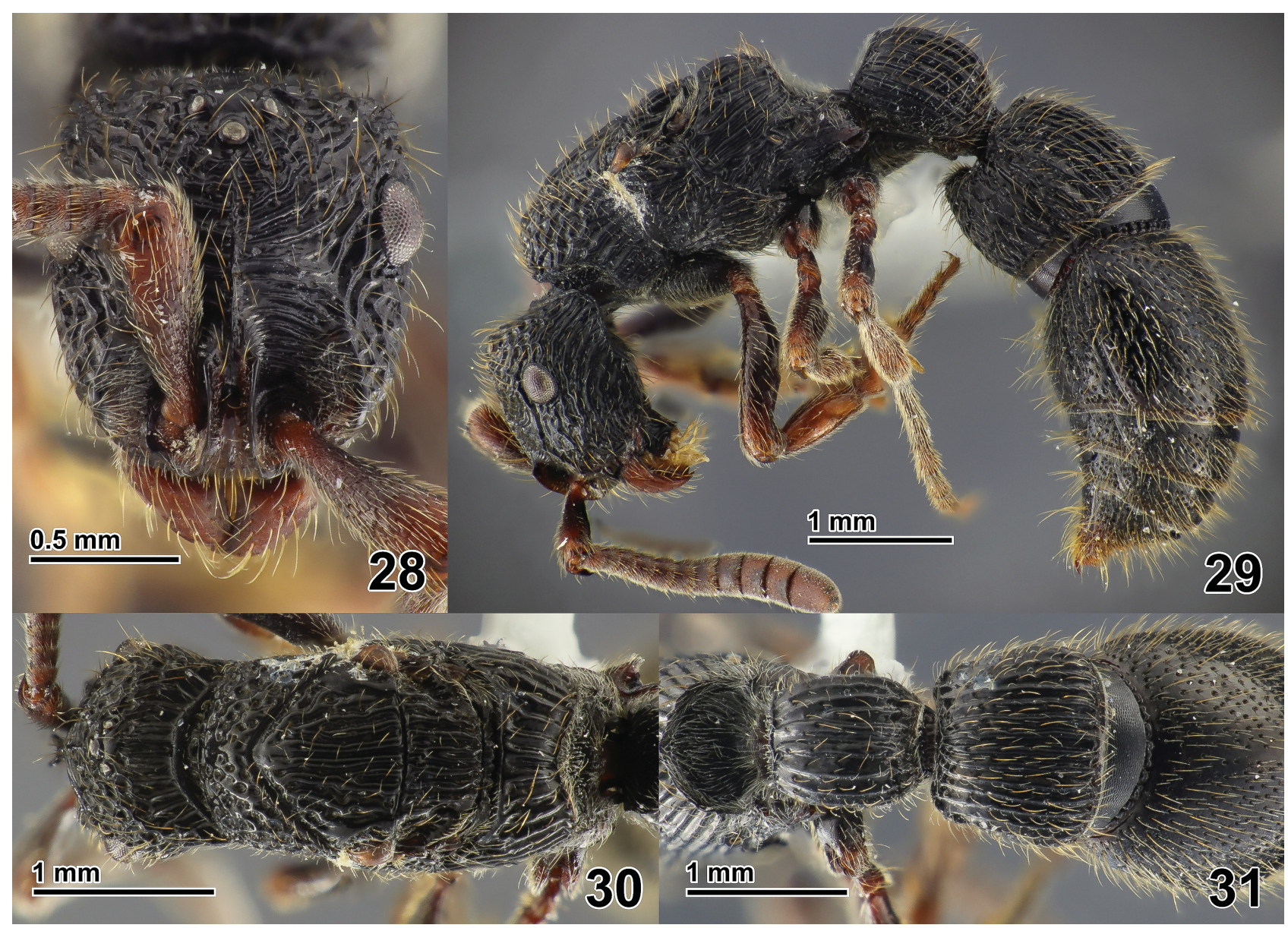

Figs 28-31. Chrysapace sauteri (Forel, 1913), nontype dealate queen from Taiwan, colony: Eg12v17-1214. 28 - head in full-face view; 29 - body in lateral view; 30 - head and mesosoma in dorsal view; 31 - metasoma in dorsal view.

margined by weak edge. Petiole in dorsal view barrel-shaped with weakly convex lateral margins. Anterodorsal corner of abdominal tergite III forming weak blunt edge in lateral view. Anteroventral corner of abdominal sternite III (prora) in lateral view weakly angulate with blunt apex. Posterior margin of pygidium in dorsal view straight.

Costae on body relatively roughly running without overlaying microsculpture. Frons transversely costate (Fig. 20). Costae on vertex coarsely obliquely running with just weak distortion. Posterolateral face of cranium and posterior face above preoccipital carina longitudinally costate (Figs 21-22). Torulo-posttorular complex and clypeus largely smooth. Gena largely smooth on face inside parafrontal ridge, whereas coarsely longitudinally costate on face outside the ridge. Outer face of antennal scape coarsely shagreened on about basal half, whereas smooth on remaining face. Outer face of mandible largely imbricate (Fig. 23). Promesonotum, mesopleuron, and dorsal and lateral faces of propodeum longitudinally costate (Figs 21-22); costae on pronotal dorsum overlaid with some coarse fovea. Posterior declivity of propodeum smooth. Legs largely smooth, with each coxa partly shagreened. Dorsal and lateral faces of petiolar tergite longitudinally costate; anterior face of petiole smooth. Posterodorsal face of helcium coarsely longitudinally costate. Abdominal tergite and sternite III longitudinally costate (Figs 21,
24). Pretergite and presternite of abdominal segment IV imbricate (Fig. 25). Cinctus of abdominal segment IV longitudinally costate. Abdominal segments IV smooth with relatively dense hair-bearing foveae. Abdominal tergites and sternites V-VI, and hypopygium imbricate on anterior marginal areas, whereas smooth with dense conspicuous hair-bearing foveae on remaining face (Fig. 27). Pygidium imbricate on anterior marginal area whereas, with dense hair-bearing foveae on remaining face (but foveae somewhat sparse in median part, Fig. 26).

Syntype worker (FOCOL0376). HL 1.14 mm; HW 0.98 mm; EL $0.22 \mathrm{~mm}$; EW $0.15 \mathrm{~mm}$; ES $0.19 \mathrm{~mm}$; OL 0.05 mm; SL 0.70 mm; WL 1.88 mm; DML 1.50 mm; MW 0.99 mm; MFL 1.05 mm; PH $0.81 \mathrm{~mm}$; PTL $0.73 \mathrm{~mm}$; PTW $0.70 \mathrm{~mm}$; A3L $0.82 \mathrm{~mm}$; A3W $1.03 \mathrm{~mm}$; CI 86; SI 72; EI 19; OI 5; DMI 66; DMI2 80; LMI 54; MFI 107; PTI 97; A3I 125 (PEHL could not be measured).

Nontype workers $(\mathrm{n}=7)$. HL 1.01-1.23 mm; HW 0.87-1.08 mm; EL 0.19-0.24 mm; EW 0.12-0.18 mm; ES 0.16-0.21 mm; PEHL 0.24-0.31 mm; OL 0.04-0.06 mm; SL 0.64-0.82 mm; WL 1.52-1.97 mm; DML 1.23-1.57 mm; MW 0.81-1.01 mm; MFL 0.92-1.23 mm; PH 0.64$0.87 \mathrm{~mm}$; PTL 0.67-0.87 mm; PTW 0.59-0.78 mm; A3L 0.70-0.96 mm; A3W 0.84-1.08 mm; CI 83-88; SI 73-78; EI 18-20; EPI 21-25; OI 4-6; DMI 64-69; DMI2 79-82; LMI 51-57; MFI 105-117; PTI 87-91; A3I 112-124. 


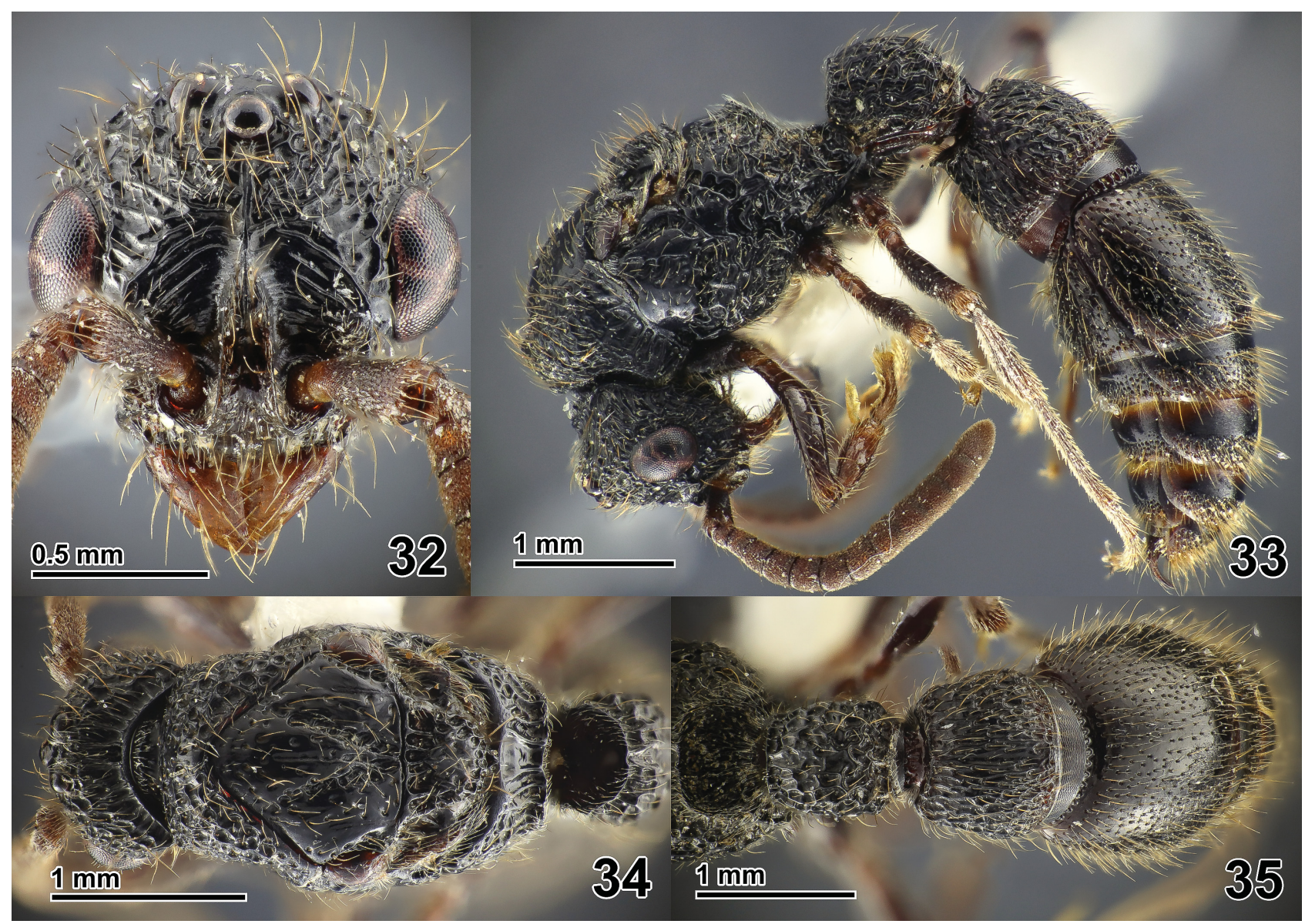

Figs 32-35. Chrysapace sauteri (Forel, 1913), nontype male from Taiwan. 32 - head in full-face view; 33 - body in lateral view; 34 - head and mesosoma in dorsal view; 35 - metasoma in dorsal view.

Queen (Figs 28-31). Body color and pilosity similar to that of worker. Body structure and sculpture similar to those of worker except for the following features: mesosoma with distinct flight-associated sclerites; dorsal outline of mesosoma almost straight; pronotum coarsely foveolate-reticulate on dorsum, whereas weakly longitudinally costate on ventrolateral face; mesoscutum without notaulus and parapsidal line; mesoscutum and mesoscutellum coarsely longitudinally costate; mesopleuron weakly coarsely longitudinally costate.

Nontype queens $(\mathrm{n}=2)$. HL 1.09-1.30 mm; HW 0.93-1.17 mm; EL 0.23-0.29 mm; EW 0.17-0.21 mm; ES 0.20-0.25 mm; PEHL 0.28-0.32 mm; OL 0.07-0.11 mm; SL 0.68-0.82 mm; WL 1.80-2.36 mm; DML 1.49-2.01 mm; MW 0.96-1.30 mm; MSL 0.55-0.83 mm; MSW 0.75-1.04 mm; MFL 0.99-1.22 mm; PTL 0.70-0.90 mm; PTW 0.63-0.81 mm; A3L 0.75-1.02 mm; A3W 0.92-1.22 mm; CI 86-90; SI 70-73; EI 21-22; EPI 24-26; OI 8-9; DMI 64-65; DMI2 83-86; MSI 126-135; MFI 104-107; PTI 90; A3I 120-123.

Male (Figs 32-40). Body black; antennae, anterior part of cranium, mandibles, and legs dark reddish brown.

Cranium in full-face view bulb-shaped, just faintly longer than wide (CI, 94-95); posterolateral corner not angulate; vertex strongly raised, with rounded convex posterior margin that completely conceals preoccipital collar in full-face view. Eye and ocelli relatively large
(EI, 35-37; OI, 12-13; EI + OI, 48-49). Median ocellus located a little posteriorly to midlength of posterior part of cranium above eyes in full-face view. Torulo-posttorular complex in full-face view relatively broad but without concealing antennal socket; width, when measured at level of antennal socket, distinctly longer than length of major axis of antennal socket; lateral margin almost straight and entirely slightly converging posteriorly; anterior protrusion of anterolateral lobe encircling antennal socket strong. Antenna 13-segmented. Maxillary palp 5-segmented. Labial palp 3-segmented. Mandible relatively short, with blunt apex; masticatory margin feebly dentate, in dorsal view distinctly less than twice as long as basal margin; ventral face of mandible with a series of modified setae along masticatory margin. Mesoscutum subpentagonal, slightly wider than long (MSI, 108-110), with faintly concave anterolateral margin; notaulus distinct as scrobiculate groove; parapsidal line present as very weak and thin furrow. Scuto-scutellar suture fairly deep and broad, strongly scrobiculate. Posterior margin of mesoscutellum in dorsal view strongly convex. Dorsal margin of propodeal declivity in dorsal view narrowly and shallowly arched anteriad, and forming strong edge. Petiole in dorsal view subrectangular, with slightly convex lateral margin. Wing venation as generic description in Borowiec (2016). Dorsal outline of abdominal tergite III in lateral view just weakly convex, with angulate 


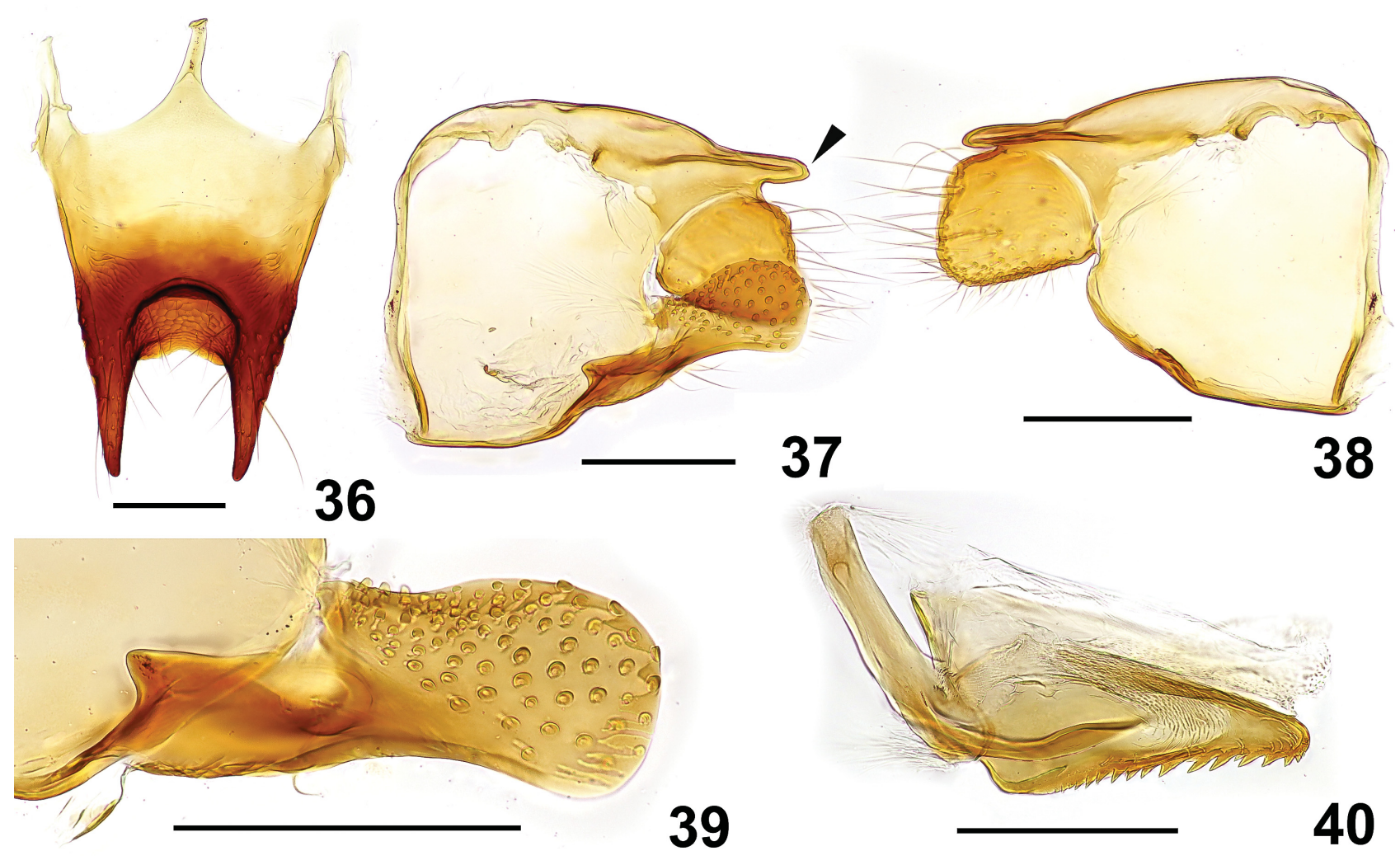

Figs 36-40. Male genitalia of Chrysapace sauteri (Forel, 1913), nontypes from Taiwan. 36 - abdominal sternite IX in ventral view; 37 - right paramere and volsella in mesal view; 38 - left paramere in mesal view, volsella removed; 39 - right volsella in mesal view; 40 - left penisvalva in lateral view. Scale bars $=0.2 \mathrm{~mm}$.

anterodorsal corner. Anteroventral corner of abdominal sternite III (prora) in lateral view weakly produced, with acute apex directed ventrad.

Frons weakly obliquely costate. Vertex and lateral and posterior faces of cranium coarsely reticulate. Posterior face above preoccipital carina longitudinally costate. Outer face of mandible imbricate. Outer face of antennal scape coarsely shagreened. Pronotum coarsely foveolate-reticulate on dorsal face, whereas weakly and coarsely longitudinally costate on lateral face. Mesopleuron largely smooth on anterodorsal face whereas coarsely and irregularly rugoso-reticulate on remaining face. Metapleuron and lateral face of propodeum coarsely and irregularly rugoso-reticulate. Mesoscutum smooth with sparse hair-bearing foveae. Mesoscutellum coarsely foveolate-reticulate, with somewhat smooth median part. Dorsum of propodeum longitudinally costate. Posterior declivity of propodeum smooth. Legs largely smooth, with each coxa partly coarsely shagreened. Anterior face of petiole smooth; dorsal and lateral faces of petiolar tergite coarsely foveolate-reticulate. Posterodorsal face of helcium coarsely longitudinally costate. Abdominal tergite and sternites III largely coarsely foveolate-reticulate. Pretergite and presternite of abdominal segment IV imbricate. Cinctus of abdominal segment IV (the boundary between pre- and postsclerites) longitudinally costate. Abdominal posttergite and poststernite IV smooth with dense hair-bearing foveae. Abdominal tergites and sternites V-VII imbricate on anterior marginal areas, whereas smooth with dense hair-bearing foveae on remaining face. Pygidium with dense hair-bearing foveae.
Spiculum (anterior apophysis) of abdominal sternite IX (Fig. 36) 0.24-0.27 times as long as entire length of sternite IX when spiculum length measured from transverse line spanning posteromost points of each anterolateral margin; lateral margin of sternite continuously straight, with posterior spine not necked basally in ventral view; posteromedian flange between bases of posterior spines broad without conspicuous foveae along anteroventral margin of flange. Posterodorsal part of basimere in lateral view strongly narrowly produced (arrow in Fig. 37); articulation of basimere to teromere without thickened margin followed by membranous articulation (Figs 37-38). Telomere in lateral view subrectangular, 1.0-1.1 times as long as wide. Cuspis absent. Digitus in lateral view subrectangular, without tapering apicad (Fig. 39). Posterior apex of valviceps in lateral view not hooked, with rounded apex; about posterior one fifth of ventral margin having 15-16 broad denticles (Fig. 40); anteroventral part of valviceps strongly produced, in lateral view not concealed by lateral apodeme.

Nontype males $(\mathrm{n}=3)$. HL $1.10-1.16 \mathrm{~mm}$; HW 1.05-1.09 mm; EL 0.41-0.46 mm; EW 0.32-0.34 mm; ES 0.37-0.40 mm; PEHL 0.33-0.34 mm; OL 0.13-0.14 mm; SL 0.43-0.44 mm; WL 2.30-2.37 mm; DML 2.03-2.13 mm; MW 1.40-1.48 mm; MSL 1.04-1.07 mm; MSW 1.11-1.15 mm; MFL 1.21-1.27 mm; PTL 0.79-0.84 mm; PTW 0.71-0.78 mm; A3L 0.83-0.87 mm; A3W 1.04-1.11 mm; CI 94-95; SI 39-41; EI 35-37; EPI 29-30; OI 12-13; DMI 69-70; DMI2 86-92; MSI 108-110; MFI 115-118; PTI 87-93; A3I 125-131. 
Distribution. Taiwan: Nantou; Chiayi; Kaohsiung (TERAYAMA et al. 1998); Pingtung (new record).

Remarks. The worker of $C$. sauteri is differentiated from its allopatric sibling species $C$. costatus by having weak distortion of costae on vertex of cranium, and distinctly smaller eye and ocelli (see also remarks for $C$. costatus below).

\section{Chrysapace costatus (Bharti \& Wachkoo, 2013)}

$$
\text { (Figs 42-48) }
$$

Chrysapace sauteri (misidentification): RADCHENKO (1993): 76, + (dealate). Unconfirmed record (see under "Remarks").

Cerapachys costatus Bharti \& Wachkoo, 2013: 1191, 9 . Type locality: "FRI [= Forest Research Institute]" (Uttarakhand, India); ChEN et al. $(2016: 8, \phi)$.

Chrysapace costatus: BOROwIEC (2016): 106 (new combination).

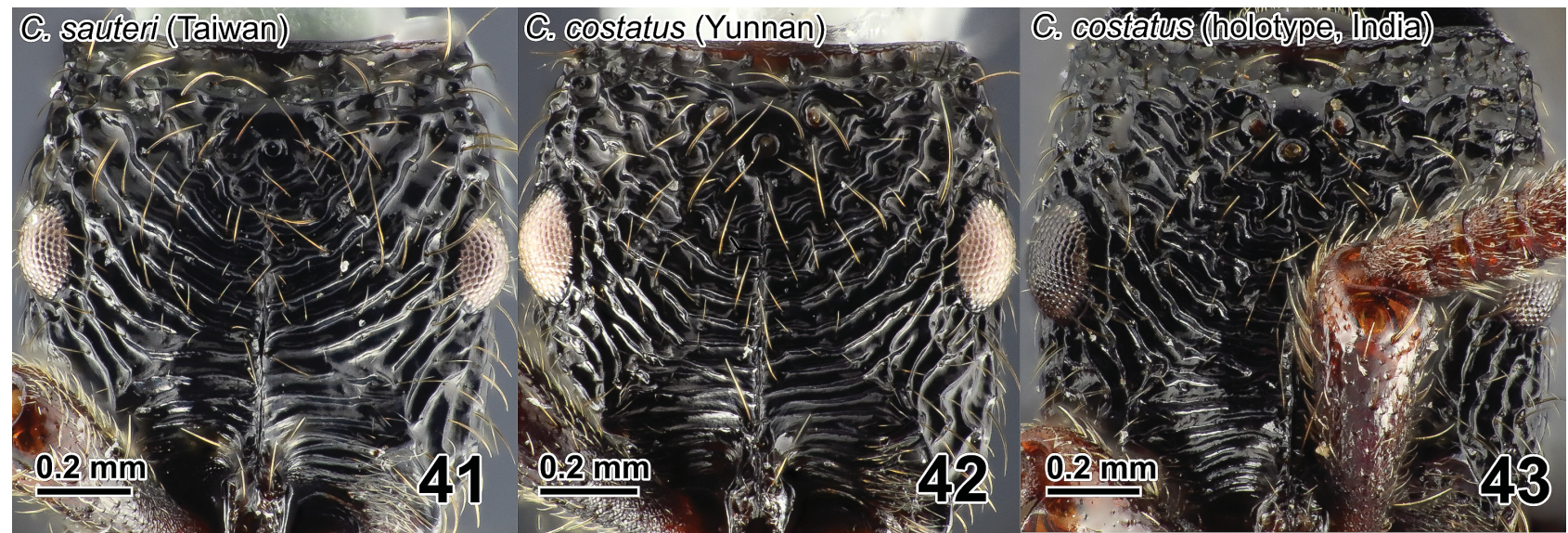

Figs 41-43. Difference of worker's head sculpture between Chrysapace sauteri (Forel, 1913) and Chrysapace costatus (Bharti \& Wachkoo, 2013). 41 - C. sauteri nontype from Taiwan, colony: Eg12v17-1214; 42 - C. costatus nontype from Yunnan; 43 - C. costatus holotype from India.

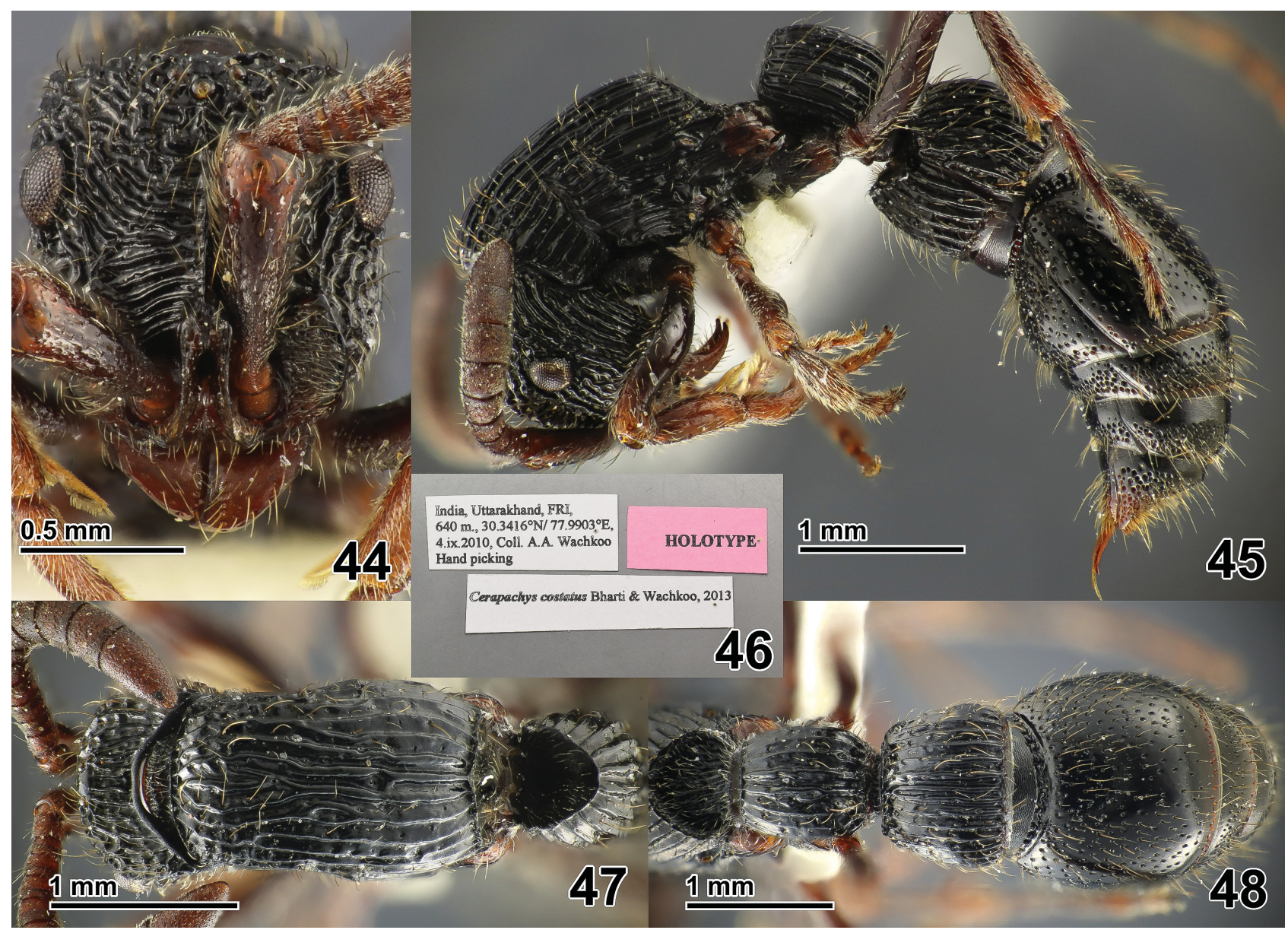

Figs 44-48. Chrysapace costatus (Bharti \& Wachkoo, 2013), holotype worker. 44 - head in full-face view; 45 - body in lateral view; 46 - label; 47 head and mesosoma in dorsal view; 48 - metasoma in dorsal view. 
Type material examined. HoLOTYPE (Figs 26-30, 33): $\stackrel{\circ}{\circ}, 30.3416^{\circ} \mathrm{N}$, $77.9903^{\circ} \mathrm{E}, 640 \mathrm{~m}$ alt., FRI, Uttarakhand, India, A.A. Wachkoo leg., 4.ix.2010 (PUPAC).

Other material examined. CHINA: GuANGxi: 3 $\not \circ, 22^{\circ} 28^{\prime} \mathrm{N}, 106^{\circ} 57^{\prime}$ E, 320 m, Nonggang Natural Reserve, Liwei Liang leg., 24.vi.2013, No. G130254 (GNU). YunNan: $3 \not ̛ \not ̛$, , Banna Wild Elephant Valley, 8.iv.2017, Chaotai Wei leg (GNU).

Material used for DNA barcoding. Individual AIK20180228-6 (accession no. LC457503), Banna Wild Elephant Valley, Yunnan, China.

Diagnosis. In the worker, cranium subrectangular in fullface view, with costae on vertex strongly and coarsely distorted; eye and median ocellus relatively large (EI, 22-24; OI, 7-8; EI + OI, 29-31); dorsum of mesosoma longitudinally costate; abdominal tergite and sternite III longitudinally costate; abdominal tergite and sternites IV smooth with relatively dense hair-bearing foveae.

Redescription. Worker (Figs 42-48). Body color, pilosity, and structure are similar to the worker of $C$. sauteri described above except for the following characteristics: costae on vertex of cranium strongly and coarsely distorted (see Figs 42-43); eye and ocelli relatively large (EI, 22-24; OI, 7-8; EI + OI, 29-31).

Holotype worker (Figs 43-48). HL 1.23 mm; HW 1.07 mm; EL 0.27 mm; EW 0.20 mm; ES 0.24 mm; PEHL 0.28 mm; OL $0.07 \mathrm{~mm}$; SL $0.81 \mathrm{~mm}$; WL $1.97 \mathrm{~mm}$; DML 1.59 mm; MW $1.06 \mathrm{~mm}$; MFL $1.17 \mathrm{~mm}$; PH $0.85 \mathrm{~mm}$; PTL $0.87 \mathrm{~mm}$; PTW $0.73 \mathrm{~mm}$; A3L $0.88 \mathrm{~mm}$; A3W $1.07 \mathrm{~mm}$; CI 87; SI 76; EI 22; EPI 22; OI 7; DMI 67; DMI2 81; LMI 53; MFI 109; PTI 85; A3I 122.

Nontype workers $(\mathrm{n}=6)$. HL $1.10-1.17 \mathrm{~mm}$; HW 0.90-0.97 mm; EL 0.23-0.26 mm; EW 0.17-0.21 mm; ES 0.21-0.23 mm; PEHL 0.24-0.29 mm; OL 0.06-0.08 mm; SL 0.65-0.70 mm; WL 1.60-1.77 mm; DML 1.25-1.32 mm; MW 0.85-0.89 mm; MFL 0.95-0.98 mm; PH 0.69$0.74 \mathrm{~mm}$; PTL 0.68-0.73 mm; PTW 0.63-0.69 mm; A3L 0.74-0.82 mm; A3W 0.90-0.95 mm; CI 81-84; SI 70-74; EI 22-24; EPI 21-25; OI 7-8; DMI 67-70; DMI2 71-80; LMI 53-59; MFI 101-105; PTI 88-98; A3I 114-122.

Distribution. Northern India: Uttarakhand, Himachal Pradesh (BHARTI \& WACHKOO 2013, BHARTI et al. 2016); China: Guangxi (CHEN et al. 2016); Yunnan (new record); Northern Vietnam? (see under "Remarks", RADCHENKO 1993).

Remarks. The original description of C. costatus (BHARTI \& WACHкоO 2013) stated that the worker of this species is easily distinguished from that of $C$. sauteri by "rectangular head with porcate-sinuate sculpture and longitudinal costate sculpture on postpetiole". However, inconsistent with this original diagnosis, the characteristics of "rectangular head" and "longitudinal costate sculpture on postpetiole" are actually shared with Taiwanese $C$. sauteri. Nevertheless, the mainland Asian populations from Yunnan, Guangxi, and India differ from the Taiwanese population (=C. sauteri) in the following morphological characteristics of the worker: the former has more strongly and coarsely distorted costae on vertex of cranium, and larger eye and ocelli than the latter. Based on these differences, we here tentatively retain the status of $C$. costatus as a distinct species, although the species delimitation needs to be tested based on more comprehensive data in the future. Pairwise distance (proportion of different sites) between Taiwanese $C$. sauteri and Yunnan C. costatus was $0.068-0.070$ in COI.

RADCHENKo (1993) recorded a dealate queen from northern Vietnam as $C$. sauteri. Identity of this specimen is currently unknown, but the geographic range suggests its affinity with $C$. costatus.

\section{Acknowledgments}

We would like to thank Mr. Hau-Chuan Liao (Tokyo Metropolitan University, Japan) and Dr. Pao-Shen Huang (Tunghai University, Taiwan) for their help with the field survey in Taiwan; Dr. Mamoru Terayama (Tokyo University, Japan) for his loan of some voucher specimens of $C$. sauteri; Dr. Zhi-Lin Chen (Guangxi Normal University, China) and Mr. Chaotai Wei for their help in examining Chinese specimens of C. costatus; Dr. Himender Bharti (Punjabi University, India) and Dr. Adam L. Cronin (Tokyo Metropolitan University, Japan) for their help in examining the holotype of C. costatus and in making linguistic corrections on the final draft; Mr. Muhammad Faisal bin Hamdan and Mr. Tuah bin Atar (Museums Department of Bruei Darussalam) for their kind help in handling the specimens of C. merimbunensis; Dr. Herbert Zettel (Natural History Museum Vienna, Austria) for his valuable comments.

\section{References}

BHARTI H., GUÉNARD B., BHARTI M. \& ECONOMO E. P. 2016: An updated checklist of the ants of India with their specific distributions in Indian states (Hymenoptera, Formicidae). ZooKeys 551: 1-83.

BHARTI H. \& WACHKOO A. 2013: Cerapachys browni and Cerapachys costatus, two new rare ant species (Hymenoptera: Formicidae) from India. Biologia 68(6): 1189-1192.

BOLTON B. 2019: An online catalog of the ants of the world. Available at http://antcat.org [Date accessed: 30 January 2019].

BOLTON B. \& FISHER B. L. 2012: Taxonomy of the cerapachyine ant genera Simopone Forel, Vicinopone gen. n. and Tanipone gen. n. (Hymenoptera: Formicidae). Zootaxa 3283: 1-101.

BOROWIEC M. L. 2016: Generic revision of the ant subfamily Dorylinae (Hymenoptera, Formicidae). ZooKeys 608: 1-280.

BOROWIEC M. L. 2017: Convergent evolution of the army ant syndrome and congruence in big-data phylogenetics. bioRxiv. https://doi. org/10.1101/134064

BOUDINOT B. 2013: The male genitalia of ants: musculature, homology, and functional morphology (Hymenoptera, Aculeata, Formicidae). Journal of Hymenoptera Research 30: 29-49.

BROWN W. L. Jr. 1975: Contributions toward a reclassification of the Formicidae. V. Ponerinae, tribes Platythyreini, Cerapachyini, Cylindromyrmecini, Acanthostichini, and Aenictogitini. Search Agriculture (Ithaca, New York) 5(1): 1-115.

CHEN Z. L., SHI F. M. \& ZHOU S. Y. 2016: A new species and a new record of Cerapachys Smith, 1857 (Hymenoptera: Formicidae) from China. Far Eastern Entomologist 324: 1-12.

CRAWLEY W. C. 1924: Ants from Sumatra, with biological notes by Edward Jacobson. Annals and Magazine of Natural History, Series 9 13: $380-409$

FOLMER O., BLACK M., HOEH W., LUTZ R. \& VRIJENHOEK R. 1994: DNA primers for amplification of mitochondrial cytochrome c oxidase subunit I from diverse metazoan invertebrates. Molecular Marine Biology and Biotechnology 3(5): 294-299.

FOREL A. 1913: H. Sauter's Formosa-Ausbeute: Formicidae II. Archiv für Naturgeschichte, Series A 79: 183-202.

HITA GARCIA F., FISCHER G., LIU C., AUDISIO T. L. \& ECONOMO E. P. 2017: Next-generation morphological character discovery and evaluation: an X-ray micro-CT enhanced revision of the ant genus 
Zasphinctus Wheeler (Hymenoptera, Formicidae, Dorylinae) in the Afrotropics. ZooKeys 693: 33-93.

HOLT B., LESSARD J. P., BORREGAARD M. K., FRITZ S. A., ARAUJO M. B., DIMITROV D., FABRE P. H., GRAHAM C. H., GRAVES G. R., JONSSON K. A., NOGUES-BRAVO D., WANG Z. H., WHITTAKER R. J., FJELDSA J. \& RAHBEK C. 2013: An update of Wallace's zoogeographic regions of the world. Science 339(6115): 74-78.

RADCHENKO A. G. 1993: Ants from Vietnam in the collection of the Institute of Zoology, PAS, Warsaw. I. Pseudomyrmicinae, Dorylinae, Ponerinae. Annales Zoologici (Warszawa) 44: 75-82.
SATRIA R., KURUSHIMA H., HERWINA H., YAMANE S. K. \& EGUCHI K. 2015: The trap-jaw ant genus Odontomachus Latreille (Hymenoptera: Formicidae) from Sumatra, with a new species description. Zootaxa 4048(1): 1-36.

TERAYAMA M., KUBOTA S., SAKAI H. \& KAWAZOE A. 1988: Rediscovery of Cerapachys sauteri Forel, 1913 (Insecta: Hymenoptera: Formicidae) from Taiwan, with notes on the Taiwanese species of the genus Cerapachys. Bulletin of the Biogeographical Society of Japan 43(7): 35-38.

WHEELER W. M. 1924: On the ant-genus Chrysapace Crawley. Psyche (Cambridge) 31: 224-225. 